\title{
Retorika Gaya Motivator dalam Pemberian Motivasi
}

\author{
Sella Desember ${ }^{1}$, Wulan Purnama Sari ${ }^{*}$ \\ ${ }^{1}$ Fakultas Ilmu Komunikasi, Universitas Tarumanagara, Jakarta \\ Email: sella.915160142@stu.untar.ac.id \\ ${ }^{2}$ Fakultas Ilmu Komunikasi, Universitas Tarumanagara, Jakarta* \\ Email:wulanp@fikom.untar.ac.id
}

Masuk tanggal : 15-12-2021, revisi tanggal : 06-01-2022, diterima untuk diterbitkan tanggal : 16-01-2022

\begin{abstract}
Rhetoric in communication is very necessary, because rhetoric is the basis for us to train our way of speaking to a wide audience. Rhetoric is also needed in the social, political, economic and educational fields. Rhetoric is very important for the motivator in conveying his motivational message. Apart from speaking the words motivator also requires oculesic and kinesic in the delivery. Motivators and characters are usually given great attention when it comes to conveying messages or words. The I'M POSSIBLE program on MetroTV, hosted by Merry Riana as a host as well as a motivator, is an inspiring, educational and motivating program. At the I'M POSSIBLE event, the writer saw that in giving motivation from Merry Riana there were aspects of rhetoric in it, because the delivery was not heavy and the topics presented were very relevant to all people then the colorful way of delivery made this program not boring. Therefore, the writer examines the rhetoric of motivator style in giving motivation (analysis on Merry Riana in the event I'M POSSIBLE on MetroTV). Based on a discussion that includes rhetoric on motivators, this study uses qualitative case study methods and semiotics to analyze every word and motion given by Merry Riana.
\end{abstract}

Keywords: kinesik, okulesik, rhetoric, semiotics

\begin{abstract}
Abstrak
Retorika dalam komunikasi sangat diperlukan, karena retorika merupakan dasar untuk individu melatih cara bicara di depan khalayak. Retorika juga diperlukan pada bidang sosial, politik, ekonomi dan pendidikan. Retorika sangat penting bagi motivator dalam menyampaikan pesan motivasinya. Selain bertutur kata motivator juga memerlukan okulesik dan kinesik dalam penyampaianya. Motivator dan para tokoh biasanya sangat diperhatikan dalam hal dia menyampaikan pesan atau kata-kata. Program acara I'm Possible di MetroTV yang dibawakan oleh Merry Riana sebagai pemandu acara sekaligus motivator merupakan sebuah program acara yang inspiratif, edukatif, dan memotivasi. Pada acara I'm Possible ini penulis melihat dalam pemberian motivasi dari Merry Riana terdapat aspek-aspek retorika didalamnya, karena penyampaiannya yang tidak berat dan topik yang dibawakan sangat relevan untuk semua masyarakat kemudian cara penyampaiannya yang penuh warna membuat program acara ini tidak membosankan. Maka dari itu, penulis meneliti retorika gaya motivator dalam pemberian motivasi pada Merry Riana dalam acara I'm Possible di MetroTV. Berdasarkan pembahasan yang meliputi retorika pada motivator, penelitian ini menggunakan metode studi kasus kualitatif dan semiotika untuk menganalisa setiap kata-kata dan gerak yang diberikan oleh Merry Riana.
\end{abstract}

Kata kunci: kinesik, okulesik, retorika, semiotika 


\section{Pendahuluan}

Setiap manusia selalu membutuhkan komunikasi antar individu maupun kelompok. Salah satu kegiatan manusia yang paling utama adalah berkomunikasi. Dengan berkomunikasi manusia dapat mendeskripsikan dan mengungkapkan apa yang ingin disampaikannya. Kemampuan berbicara bisa jadi merupakan bakat. Kepandaian berbicara yang baik memerlukan pengetahuan dan latihan.

Setiap khalayak pasti sering memperhatikan cara dan gaya berpakaian orang, dan yang paling penting memperhatikan cara dan bertutur yang baik. Di sinilah retorika sebagai "ilmu berbicara" yang diperlukan oleh semua orang. Retorika (rhetoric, rhetorica) sering dipahami sebagai ilmu berpidato (the art of oratory). Seni penggunaan bahasa secara efektif (the art of using language effectively). Seni berbicara didapatkan melalui talenta dan ketrampilan teknis. Retorika merupakan ilmu dan seni yang mengajarkan orang untuk pandai dalam menyusun kalimat yang efektif. Retorika juga merupakan seni untuk "memanipulasi" percakapan (the art of fake speech) (Sutrisno dan Wiendijarti, 2015)

Retorika atau public speaking menjadi sesuatu yang penting untuk dipelajari. Keberhasilan seorang komunikator juga terpengaruh oleh bagaimana komunikator itu menyampaikan pesannya, apakah komunikator berhasil meyakinkan para khalayaknya dengan segala yang terlihat maupun terdengar.

Retorika diartikan juga sebagai kesenian berbicara yang baik, yang digunakan dalam proses komunikasi anttarmanusia. Seni bicara ini bukan hanya berarti berbicara lancar tanpa adanya jalan berpikir yang jelas dan tanpa esensi. Tetapi juga suatu kemampuan untuk berbicara dengan singkat,jelas,dan padat. Menurut Hendrikus (2015) retorika sebagai bagian ilmu berbicara terdiri dari tiga bagian yaitu: monologika, dialogika, dan pembinaan teknik bicara. Monologika adalah ilmu tentang seni dalam berbicara secara monolog hanya satu orang saja yang berbicara, bentukbentuk yang termasuk monologika seperti pidato,ceramah dan deklamasi. Dialogika adalah ilmu bicara yang melibatkan dua orang atau lebih dalam sebuah pembicaraan. Bentuk dialogika adalah diskusi, debat, dan tanya jawab. Teknik bicara merupakan efektivitas monologika dan dialogika akan tetapi tergantung pada teknik bicara. Teknik bicara adalah bagian yang paling penting dalam retorika.

Penelitian ini juga termasuk bagian kerangka bicara dialogika, seiring dengan berkembangnya teknologi dialogika yang terbentuk tanya jawab banyak sekali ditemukan ditelevisi seperti dalam acara talk show. Talk Show merupakan program jurnalistik yang menampilkan perbincangan satu atau beberapa orang sebagai narasumber untuk membahas sebuah topik atau masalah tertentu yang dibawa oleh pembawa acara atau host. Narasumber yang diundang adalah orang-orang yang memiliki pengalaman langsung dengan topik atau permasalahan yang sedang dibahas. Semua hal tersebut dilakukan agar memperoleh informasi dan fakta yang jelas dan akurat (Atikasari,2019).

Salah satu acara talk show yang selalu memotivasi yang membahas masalah dan peristiwa yang hangat di Indonesia dengan tema lama yang masih menarik untuk dibahas adalah I'm Possible. I'm Possible merupakan sebuah acara yang dibawakan oleh Merry Riana. Merry Riana adalah seorang penulis, pembicara, trainer, dan menjadi seorang motivator di Indonesia. Merry Riana juga seorang enterpreneur dan dijuluki wanita sejuta dolar. Acara I'm Possible yang dibawakan langsung oleh Merry Riana tayang pukul 19.05 - 20.00 WIB. Aacara I'm Possible selalu konsisten menghadirkan topik dan permasalahan yang menarik dengan narasumber yang 
inspiratif dengan tujuan dapat memberikan inspirasi, motivasi dan solusi kepada khalayaknya. Merry Riana selalu fokus untuk bertanya pada narasumbernya sesuai dengan topik yang dibahas pada saat itu.

Seorang pemandu acara atau motivator harus memiiliki kemampuan retorika yang baik. Dalam memilih kata (diksi) yang sesuai dengan pembicaraan acara tersebut. Diksi adalah pemilihan kata yang tepat dan sesuai yang digunakan untuk menyampaikan sebuah pandangan (Atikasari,2019). Dalam acara I'm Possible diksi yang digunakan adalah diksi yang mudah dipahami oleh khalayak. Hal tersebut membuat diksi di acara I'm Possible menjadi menarik untuk diteliti.

Merry Riana juga menggunakan retorika bertanya agar informasi yang didapatkan jelas dan akurat. Salah satu teknik bertanya yang digunakan adalah yang berkaitan dengan pertanyaan yang diberikan oleh Merry Riana kepada narasumber. Selain tempat untuk memperoleh informasi, pertanyaan menjadi hal yang paling penting dalam sebuah talk show karena pertanyaan dapat dijadikan sebuah acuan untuk mengaktifkan permasalahan yang akan dibahas. Pertanyaan dapat menjadi sarana untuk membangun inisiatif bahkan mensugesti komunikasi anatar manusia (Hendrikus, 2015).

Informasi yang jelas dan akurat dari narasumber dalam acara I'm Possible tidak terlepas dari retorika bertanya yang berkaitan dengan kinesik dan okulesik dari Merry Riana. Kinesik merupakan bentuk dari komunikasi nonverbal yang berupa gerakan dari tubuh dan gerakan tangan yang bermakna dan mendukung proses komunikasi lisan tatap muka, sedangkan okulesik merupakan bentuk dari komunikasi nonverbal berupa tatap mata dan wajah yang penuh makna dan mendukung proses komunikasi lisan tatap muka.

Kinesik dan okulesik sangat penting nilainya dalam proses komunikasi lisan tatap muka karena dapat memperkuat dan memperjelas pesan yang akan disampaikan secara verbal. Merry Riana memanfaatkan okulesik dan kinesik dalam retorika bertanya untuk menunjang proses penyampaian pesan dalam pembicaraannya sehingga memperoleh informasi yang jelas dan akurat dari narasumber.

Retorika bertanya Merry Riana dalam acara I'm Possible di MetroTV menarik untuk diteliti karena berbagai alasan. Pada saat Merry Riana bertanya kepada narasumber dalam acara I'm Possible terdapat beberapa strategi bertanya yang digunakan Merry Riana untuk memperoleh informasi yang jelas dan akurat dari narasumber. Kehadiran Merry Riana membuat acara televisi di Indonesia lebih bermanfaat dan variatif. Tidak hanya berfungsi sebagai media informatif dan menghibur, selain itu acara I'm Possible juga sebagai media yang edukatif.

\section{Metode Penelitian}

Peneliti menggunakan semiotika Roland Barthes. Dalam analisis semiotika Roland Barthes ini, penulis menganalisis tiga tanda yaitu visual, verbal, serta audio, yang kemudian nantinya akan dihubungkan sehingga dapat menarik makna denotatif dan konotatifnya yang kemudian akan menghasilkan ideologi. Peneliti memilih metode semiotika Roland Barthes karena metode ini dapat membantu peneliti dalam menganalisa tanda visual, verbal, serta audio yang terdapat retorika Merry Riana di video - video motivasi dalam acara I'm Possible di MetroTV kemudian akan ditarik makna denotatif serta makna konotatifnya, yang nantinya akan menunjukkan ideologi yang ingin disampaikan dalam video motivasi Merry Riana dalam acara I'm Possible di MetroTV. 
Barthes berpendapat bahasa merupakan sebuah sistem tanda yang mencerminkan asumsi-asumsi dari suatu masyarakat tertentu, serta dalam waktu tertentu (Sobur, 2013). Sistem pemaknaan tingkat pertama disebut dengan denotatif, dan sistem pemaknaan tingkat kedua disebut dengan konotatif. Dalam penelitian retorika gaya motivator dalam pememberian motivasi (analisis pada Merry Riana dalam acara I'm Possible di MetroTV) dalam pandangan semiotika Roland Barthes, bertujuan untuk memberikan pemahaman tentang retorika-retorika yang digunakan motivator Merry Riana dalam acara I'm Possible melalui bentuk-bentuk visual, verbal, serta audio yang ada pada ritual tersebut, yang pada akhirnya akan menunjukkan retorika yang digunakan oleh Merry Riana dalam menyampaikan motivasinya.

\section{Hasil Temuan dan Diskusi}

Program acara I'm Possible adalah program acara yang berbentuk gelar wicara/talkshow yang dimana program ini berbagi inspirasi dan motivasi untuk penontonnya. Acara ini dipandu oleh Merry Riana sebagai motivator dibantu Irgi Fahrezi sebagai host. Program acara ini tayang setiap Sabtu pukul 19.05 - 20.00 WIB di MetroTV. Program acara I'm Possible selalu mengundang narasumber yang inspiratif sesuai dengan topik yang dibahas yang bertujuan memberikan inspirasi, motivasi dan solusi yang bisa diaplikasikan ke dalam kehidupan sehari-hari.

Program tersebut mempunyai tema yang berbeda-beda setiap minggunya, salah satunya dalam Tema Titik Terendah. Merry Riana menjelaskan dalam tema titik terendah bahwa pada saat kita berada dalam titik terendah dalam hidup kita, yang kita bisa rasakan hanyalah perasaan negatif seperti sedih, gelisah, kehilangan energi dan motivasi. Dalam tema ini Merry Riana juga membahas mengapa hal itu bisa terjadi, apa yang harus kita lakukan ketik kita berada dititik terendah, dan bagaimana caranya kita bangkit dari masalah tersebut. Yang artinya acara I'm Possible ini memberikan solusi sekaligus solusi untuk setiap masalah yang ada. Terendah:

Sajian data berupa scene Program I'm Possible di MetroTV Episode Titik

Tabel 1. Scene Program I'm Possible Di Metrotv Episode Titik Terendah

\begin{tabular}{|c|c|c|c|c|}
\hline Episode & Scene & Sign & Interpretasi & Teks \\
\hline $\begin{array}{l}\text { Titik } \\
\text { Terendah } \\
\text { (part } 1)\end{array}$ & 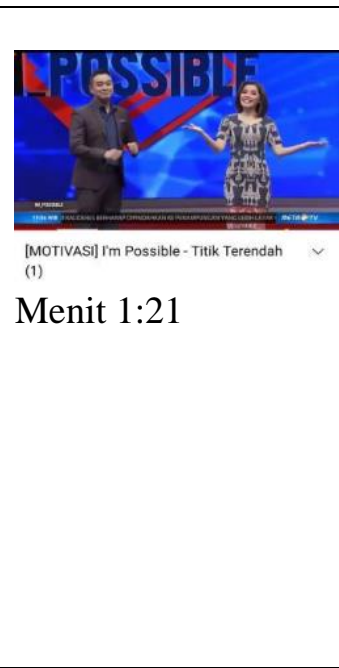 & $\begin{array}{l}\text { Kedua } \\
\text { tangan Miss } \\
\text { Merry Riana } \\
\text { terbuka }\end{array}$ & $\begin{array}{l}\text { Miss Merry Riana } \\
\text { sedang menyapa } \\
\text { pemirsa yang ada } \\
\text { distudio dan yang } \\
\text { dirumah yang } \\
\text { mengartikan } \\
\text { bahwa gerak } \\
\text { tangan tersebut } \\
\text { menandakan } \\
\text { Merry Riana } \\
\text { sedang } \\
\text { menyambut } \\
\text { pemirsa dan } \\
\text { Merry Riana } \\
\text { sangat welcome }\end{array}$ & $\begin{array}{l}\text { Miss Merry } \\
\text { Riana: Dan } \\
\text { selamat malam } \\
\text { pemirsa semua } \\
\text { yang ada distudio } \\
\text { dan juga dirumah. } \\
\text { Senang sekali } \\
\text { setiap minggu } \\
\text { kami hadir bukan } \\
\text { hanya } \\
\text { memberikan } \\
\text { inspirasi tapi juga } \\
\text { solusi lewat tema- } \\
\text { tema yang kami } \\
\text { angkat setiap }\end{array}$ \\
\hline
\end{tabular}




\begin{tabular}{|c|c|c|c|c|}
\hline & & & $\begin{array}{l}\text { dengan pemirsa } \\
\text { yang ada distudio } \\
\text { dan yang } \\
\text { dirumah. }\end{array}$ & $\begin{array}{l}\text { minggunya. } \\
\text { Karena kami } \\
\text { percaya tidak ada } \\
\text { yang tidak } \\
\text { mungkin, dari } \\
\text { impossible jadi? } \\
\text { pemirsa: I'm } \\
\text { possible!! }\end{array}$ \\
\hline \multirow[t]{2}{*}{$\begin{array}{l}\text { Titik } \\
\text { terendah } \\
\text { (part } 1)\end{array}$} & 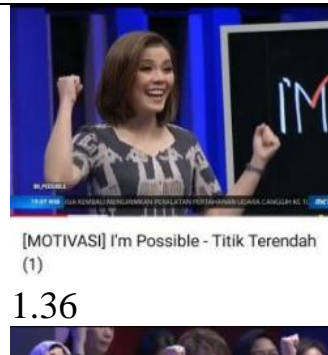 & $\begin{array}{l}\text { Miss Merry } \\
\text { Riana: } \\
\text { mengangkat } \\
\text { tangan yang } \\
\text { dikepal } \\
\text { keatas }\end{array}$ & $\begin{array}{l}\text { Merry Riana } \\
\text { berinteraksi } \\
\text { dengan penonton } \\
\text { distudio dan } \\
\text { mengajak untuk } \\
\text { mengucapkan } \\
\text { slogan acara I'm } \\
\text { Possible }\end{array}$ & $\begin{array}{l}\text { Miss Merry } \\
\text { Riana: Karena } \\
\text { kami percaya } \\
\text { tidak ada yang } \\
\text { tidak mungkin, } \\
\text { dari impossible } \\
\text { jadi? }\end{array}$ \\
\hline & $\begin{array}{l}\text { [MotTVASI] Im Possible - Ttikik Terendah } \\
\text { (1) } \\
1.37\end{array}$ & $\begin{array}{l}\text { Penonton } \\
\text { distudio: } \\
\text { mengikuti } \\
\text { yang } \\
\text { dilakukan } \\
\text { oleh Miss } \\
\text { Merry Riana }\end{array}$ & & $\begin{array}{l}\text { Penonton: I'm } \\
\text { Possible!! }\end{array}$ \\
\hline $\begin{array}{l}\text { Titik } \\
\text { terendah } \\
(\text { part } 1)\end{array}$ & $=$ & $\begin{array}{l}\text { Tangan Miss } \\
\text { Merry Riana } \\
\text { menunjuk } \\
\text { keatas. }\end{array}$ & $\begin{array}{l}\text { Mengartikan } \\
\text { bahwa Miss } \\
\text { Merry Riana } \\
\text { sedang menunjuk } \\
\text { keatas sesuai } \\
\text { ucapannya yang } \\
\text { bilang kadang } \\
\text { hidup diatas, } \\
\text { tanda ini } \\
\text { digunakan agar } \\
\text { khalayak } \\
\text { menangkap dan } \\
\text { mengingat } \\
\text { dengan mudah. }\end{array}$ & $\begin{array}{l}\text { Miss Merry } \\
\text { Riana: hidup } \\
\text { itukan naik turun, } \\
\text { kadang kita di atas } \\
\text { kadang kita } \\
\text { dibawah. }\end{array}$ \\
\hline
\end{tabular}




\begin{tabular}{|c|c|c|c|c|}
\hline $\begin{array}{l}\text { Titik } \\
\text { terendah } \\
\text { (part } 1 \text { ) }\end{array}$ & 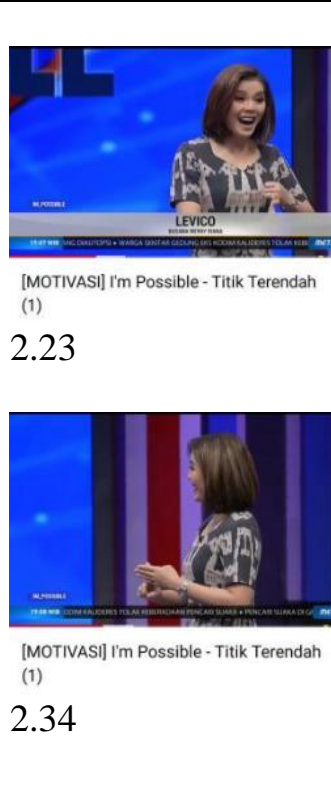 & $\begin{array}{l}\text { Menjelaskan } \\
\text { faktor-faktor } \\
\text { penyebab } \\
\text { keterpurukan } \\
\text { Miss Merry } \\
\text { Riana } \\
\text { menjelaskan } \\
\text { satu persatu } \\
\text { dengan } \\
\text { memakai jari } \\
\text { tangan. }\end{array}$ & $\begin{array}{l}\text { Miss Merry Riana } \\
\text { menggunakan jari } \\
\text { tangan untuk } \\
\text { memudahkan } \\
\text { penonton untuk } \\
\text { mengingat satu } \\
\text { persatu faktor- } \\
\text { faktor } \\
\text { keterpurukan } \\
\text { yang disebutkan, } \\
\text { seperti mendikte } \\
\text { satu persatu } \\
\text { faktor } \\
\text { keterpurukan } \\
\text { tersebut agar } \\
\text { mudah ditangkap } \\
\text { oleh penonton } \\
\text { (okulesik) }\end{array}$ & $\begin{array}{l}\text { Miss Merry } \\
\text { Riana: } \\
\text { keterpurukan itu } \\
\text { bisa terjadi } \\
\text { dengan berbagai } \\
\text { macam alasan, } \\
\text { kadang-kadang } \\
\text { bisa terpuruk } \\
\text { karena } \\
\text { usaha,terpuruk } \\
\text { karena cita-cita } \\
\text { yang hancur } \\
\text { berantakan,terpur } \\
\text { uk karena kondisi } \\
\text { keuangan dan } \\
\text { juga terpuruk } \\
\text { karena cinta. }\end{array}$ \\
\hline $\begin{array}{l}\text { Titik } \\
\text { terendah } \\
\text { (part 1) }\end{array}$ & $\begin{array}{l}\text { IMOTVASII I'm Possible- - Triki Terendah } \\
\text { (1) } \\
9.20\end{array}$ & $\begin{array}{l}\text { Saat } \\
\text { menyampaik } \\
\text { an sebuah } \\
\text { kalimat } \\
\text { motivasi } \\
\text { Miss Merry } \\
\text { Riana selalu } \\
\text { mengerakkan } \\
\text { tangan dan } \\
\text { menggunaka } \\
\text { n bahasa } \\
\text { tubuh. }\end{array}$ & $\begin{array}{l}\text { Selain } \\
\text { menyampaikanny } \\
\text { a lewat tutur kata } \\
\text { Miss Merry Riana } \\
\text { juga } \\
\text { menggunakan } \\
\text { bahasa tubuh } \\
\text { untuk menunjang } \\
\text { penyampaian } \\
\text { pesan } \\
\text { motivasinya agar } \\
\text { tersampaikan dan } \\
\text { penonton bisa } \\
\text { terbawa alur } \\
\text { emosi yang } \\
\text { disampaikan. }\end{array}$ & $\begin{array}{l}\text { Miss Merry } \\
\text { Riana: saya } \\
\text { jadikan titik } \\
\text { terendah itu } \\
\text { sebagai pondasi } \\
\text { untuk saya } \\
\text { membangun } \\
\text { mimpi-mimpi } \\
\text { saya dan akhirnya } \\
\text { saya bisa berhasil } \\
\text { dan saya juga } \\
\text { yakin, bila saya } \\
\text { berhasil as bobby } \\
\text { juga bisa berhasil. }\end{array}$ \\
\hline
\end{tabular}

Sumber: Pengolahan Data oleh Peneliti

\section{Simpulan}

Retorika merupakan hal yang penting untuk digunakan dalam kehidupan berkomunikasi sehari-hari. Karena jika tidak ada retorika komunikasi akan terasa hambar dan biasa. Retorika gaya motivator juga sangat berpengaruh, karena ada banyak motivator-motivator yang ada di Indonesia membuat kita bisa memilih motivator mana yang paling bagus dalam menyampaikan atau membagikan motivasinya. Retorika yang digunakan Merry Riana dalam acara I'm Possible di MetroTV dalam menyampaikan motivasinya tidak terlalu berat sehingga khalayak mudah menerima pesan tersebut dengan sangat mudah.

Setelah membahas semiotika pada acara I'm Possible kita menjadi tahu bahwa setiap penyampaian motivasinya selalu terkandung retorika, okulesik dan kinesik. Selain bertutur kata, motivator Merry Riana juga menggunakan okulesik dan kinesik dalam penyampaian motivasinya sehingga kita mudah untuk menangkap pesan yang disampaikannya dengan mudah. Okulesik dan kinesik yang digunakan seperti gerakan 
tangan, bahasa tubuh dan ekpresi wajah. Retorika merupakan hal yang sangat penting bagi Merry Riana sebagai seorang motivator dalam acara I'm Possible di MetroTV karena pembawaan dari Merry Riana selaku motivator sangat inspiratif, edukatif, dan memotivasi banyak orang diluar sana yang membutuhkan solusi dan motivasi, selain itu pembawaannya yang fresh, kreatif dan kekinian membuat program acara ini berbeda dengan yang lainnya.

\section{Ucapan Terima Kasih}

Penulis mengucapkan ucapan terima kasih yang sebesar-besarnya kepada para narasumber dan seluruh pihak yang telah membantu penulis dalam melaksanakan penelitian ini sampai dengan selesai.

\section{Daftar Pustaka}

Alberico, Jerry. (2019). Retorika Deliberatif Selebgram dalam Memotivasi Audiens Melalui Media Sosial (Konten "Level Up" di Akun Instagram Benakribo). Skripsi. Jakarta: Ilmu Komunikasi Universitas Tarumanagara

Atikasari, Frida Ayu. (2019). Retorika Bertanya Merry Riana Dalam Acara I'm Possible di MetroTV. 8-24. Diakses dari https://repository.unej.ac.id/handle/123456789/93710

Bungin, Burhan. (2015). Metodologi Penelitian Kualitatif. Depok: Rajagrafindo Pustaka.

Creswell, J. W. (2010). Research Design: Pendekatan Kualitatif, Kuantitatif dan Mixed. Yogyakarta: PT Pustaka Pelajar

Emzir. (2016). Metodologi Penelitian Kualitatif Analisis Data. Jakarta: PT Raja Grafindo Persada

Jannah. Roihul. (2018). Strategi Retorika Bertanya Andy F. Noya Dalam Acara Kick Andy Di Metrotv Dan Pemanfaatannya Sebagai Alternatif Pengembangan Materi Ajar Teks Berita Di SMP Kelas VII. 12-31

Moleong, Lexy J. (2009). Metode Penelitian Kualitatif. Bandung: Remaja Rosdakarya Mukoyimah. (2018). Retorika Dalam Pidato Soekarno Pada Demokrasi Terpimpin. 28-32

Nazir, Mohammad. (2013). Metode Penelitian. Bogor: Ghalia Indonesia

Sugiyono. (2009). Metode Penelitian Kuantitatif, Kualitatif dan R\&D. Bandung: Alfabeta

Sulistyowati. Fristin. Intan. (2020). FENTY EFFENDY DALAM TAYANGAN PROGRAM BUKA BUKU DI NARASI TV (Analisis Retorika Prinsip Hukum Kanon). 17-21

Sutrisno, Isbandi dan Ida Wiendijarti. (2015). Kajian Retorika Untuk Pengembangan Pengetahuan dan Ketrampilan Berpidato. Jurnal Ilmu Komunikasi. 71-74 